\title{
A commentary on the efficacy of olanzapine for the treatment of schizophrenia: the past, present, and future
}

This article was published in the following Dove Press journal:

Neuropsychiatric Disease and Treatment

\author{
Leslie Citrome ${ }^{\prime}{ }^{\prime}$ \\ Joseph P McEvoy ${ }^{2}$ \\ Mark S Todtenkopf $\mathbb{D}^{3}$ \\ David McDonnell ${ }^{4}$ \\ Peter J Weiden $\mathbb{1}^{3}$ \\ 'Department of Psychiatry and \\ Behavioral Sciences, New York Medical \\ College, Valhalla, NY, USA; ${ }^{2}$ Department \\ of Psychiatry and Health Behavior, \\ Medical College of Georgia, Augusta \\ University, Augusta, GA, USA; \\ ${ }^{3}$ Alkermes, Inc., Waltham, MA, USA; \\ ${ }^{4}$ Alkermes Pharma Ireland Ltd., Dublin, \\ Ireland
}

\begin{abstract}
Olanzapine is a second-generation atypical antipsychotic with proven efficacy for the treatment of schizophrenia. Approved in 1996, olanzapine is one of the most studied antipsychotics, resulting in a considerable amount of clinical data across diverse patient populations. Despite the fact that olanzapine is associated with a known risk of metabolic side effects, including weight gain, many clinicians continue to prescribe olanzapine for the treatment of schizophrenia with the expectation of additional therapeutic antipsychotic efficacy relative to other first-line atypical antipsychotics. The goal of this narrative is to revisit the role of oral olanzapine in the management of patients with schizophrenia, including those with recently diagnosed schizophrenia ("first-episode"), those with an established schizophrenia diagnosis who experience acute exacerbations, those receiving long-term antipsychotic treatment as a maintenance intervention, and those with suboptimal response to antipsychotic treatment, including treatment resistance. Collectively, data from published literature support the favorable efficacy of olanzapine compared with other first- and secondgeneration antipsychotics, including lower rates of treatment discontinuation and clinically meaningful improvements in the symptoms of schizophrenia. The development of antipsychotic medications with the favorable efficacy of olanzapine, but with reduced weight gain, could address a major unmet need in the treatment of schizophrenia.
\end{abstract}

Keywords: antipsychotic, efficacy, metabolic dysregulation, weight gain

\section{Introduction}

Olanzapine is an atypical antipsychotic first approved by the US Food and Drug Administration (FDA) in September 1996 for the treatment of schizophrenia. ${ }^{1,2}$ The availability of olanzapine and the atypical class in general provided psychiatrists with treatment options with reduced risk of motoric adverse effects. ${ }^{3}$ Several metaanalyses have been published establishing the efficacy and minimal extrapyramidal adverse effects with olanzapine compared to typical and some atypical antipsychotics in the treatment of schizophrenia. ${ }^{4-6}$ However, due to the risk of metabolic dysregulation and weight gain, most guidelines have positioned olanzapine as a second-choice therapy for the treatment of schizophrenia. ${ }^{7-11}$ This is similar to clozapine, which, despite its established efficacy for treatment-resistant symptoms, is positioned last because of safety concerns. ${ }^{11,12}$ Many experienced clinicians are of the opinion that olanzapine offers a distinctly favorable efficacy profile among the currently available antipsychotic medications, ${ }^{4-6,13}$ and therefore continue to prescribe the drug for patients with schizophrenia. This narrative review revisits the
Correspondence: Leslie Citrome II Medical Park Drive, Suite 106, Pomona, NY 10970, USA

$\mathrm{Tel}+\mathrm{I} 8453622081$

Email citrome@cnsconsultant.com 
role of oral olanzapine in the management of adults with schizophrenia, examining evidence supporting the additional efficacy of olanzapine from the published literature since its initial approval.

\section{Initial discovery and preclinical data}

Olanzapine was first discovered while searching for a chemical analog of clozapine that would not require hematological monitoring. While investigating a series of thiophene isosteres on 1 of the phenyl rings in clozapine, a thienobenzodiazepine analog (olanzapine) was discovered. ${ }^{1,14,15}$ The receptor binding affinities for olanzapine were determined using in vitro assays ${ }^{16}$ and confirmed by in vivo functional assays. ${ }^{17}$ Olanzapine has high binding affinity for D1, D2, D4, 5HT2A, 5HT2C, 5HT3, $\alpha-1$ adrenergic, histaminergic, and muscarinic receptors, which mirrors that of clozapine. ${ }^{16}$ In functional studies, olanzapine was a potent antagonist at 5HT and D2 receptors, suggesting it might be useful as an antipsychotic agent. ${ }^{17}$ In animal models, olanzapine produced antagonism of apomorphine-induced climbing and conditioned avoidance responding in rats, suggesting dopaminergic effects; antagonism of 5-hydroxytryptophan-induced head twitching and blockade of oxotremorine-induced tremor in mice indicate serotonergic and anticholinergic activity, respectively. ${ }^{18}$ In addition, although not binding directly, research has indicated that olanzapine modulates $N$-methyl-D-aspartate (NMDA) receptors. ${ }^{19,20}$ These preclinical studies provided strong evidence that olanzapine could potentially be an effective antipsychotic drug with less drug-induced motoric activation associated with the existing antipsychotics at the time (see Safety section). ${ }^{18,21}$ The clinical pharmacokinetic profile of olanzapine supported once-daily oral administration, starting with a dose of 5-10 mg, with a target dose of $10 \mathrm{mg} /$ day, and a maximum dose of $20 \mathrm{mg} /$ day. ${ }^{1}$ Taken together, the preclinical and pharmacokinetic data helped to support the full clinical development and eventual approval of olanzapine for the treatment of schizophrenia. ${ }^{2}$

The approval of olanzapine in schizophrenia was initially based on data from short-term controlled trials (6 weeks). ${ }^{22}$ A longer-term maintenance trial (up to 8 months) of adults who met DSM-III-R/DSM-IV criteria for schizophrenia was later conducted. ${ }^{1}$ Since its approval over 2 decades ago, olanzapine has been one of the most investigated drugs in its class, leading to the generation of a considerable amount of clinical data on its efficacy and safety in patients with schizophrenia and other indications. ${ }^{1,3,23}$

\section{Assessment of antipsychotic effects}

Schizophrenia is a chronic disease with a diverse psychopathology and multiple phases of illness. ${ }^{11,24}$ Consequently, numerous factors must be considered when assessing the benefits of a given treatment over short- and long-term periods. ${ }^{11,25}$ A number of scales and instruments are used in clinical trials of schizophrenia to assess treatment efficacy; these have been reviewed in detail elsewhere. ${ }^{26-29}$ Improvements in the psychopathologic symptoms of schizophrenia ${ }^{26}$ are commonly assessed using the 18-item Brief Psychiatric Rating Scale (BPRS), ${ }^{30}$ the Clinical Global Impression (CGI) scale, ${ }^{29,31}$ or the 30 -item Positive and Negative Syndrome Scale (PANSS). ${ }^{32}$ Another well-recognized measure of treatment effectiveness that takes into consideration not only efficacy and tolerability but also patient experience is all-cause discontinuation. ${ }^{33-35}$ The effect of antipsychotic treatment on hostility, given its close relationship to aggression and nonadherence to treatment, ${ }^{36}$ has also been extensively studied, ${ }^{37}$ commonly by examining treatment-associated changes to the hostility item of the PANSS ${ }^{32}$ or BPRS ${ }^{30}$ as a proxy measure of aggression.

Here, we summarize key evidence for the efficacy of olanzapine across various stages of treatment in patients with schizophrenia (Table 1).

\section{First-episode schizophrenia}

Patients presenting with a first psychotic episode require prompt administration of an effective antipsychotic medication to minimize the duration of untreated psychosis. ${ }^{11}$ The first episode of psychosis can be polymorphic and may evolve into a variety of conditions other than schizophrenia, with associated prognostic implications. Regardless of the eventual diagnosis, early intervention during a psychotic episode may prevent future deterioration and progression toward chronicity. ${ }^{11}$

Several studies have provided evidence of olanzapine's efficacy in first-episode schizophrenia patients. ${ }^{38-41}$ Notably, patients treated with olanzapine were less likely to discontinue treatment compared with other antipsychotics. In the largescale European First-Episode Schizophrenia Trial (EUFEST), olanzapine had the lowest rate of all-cause discontinuation (Figure 1) at 1 year (33\%) compared with haloperidol (72\%), quetiapine (53\%), ziprasidone (45\%), and amisulpride $(40 \%) .{ }^{40}$ In a separate trial, nearly 2 times as many patients remained on olanzapine (23\%) compared with haloperidol $(12 \%)$ at 2 years. ${ }^{39}$ In both studies, treatment with olanzapine 


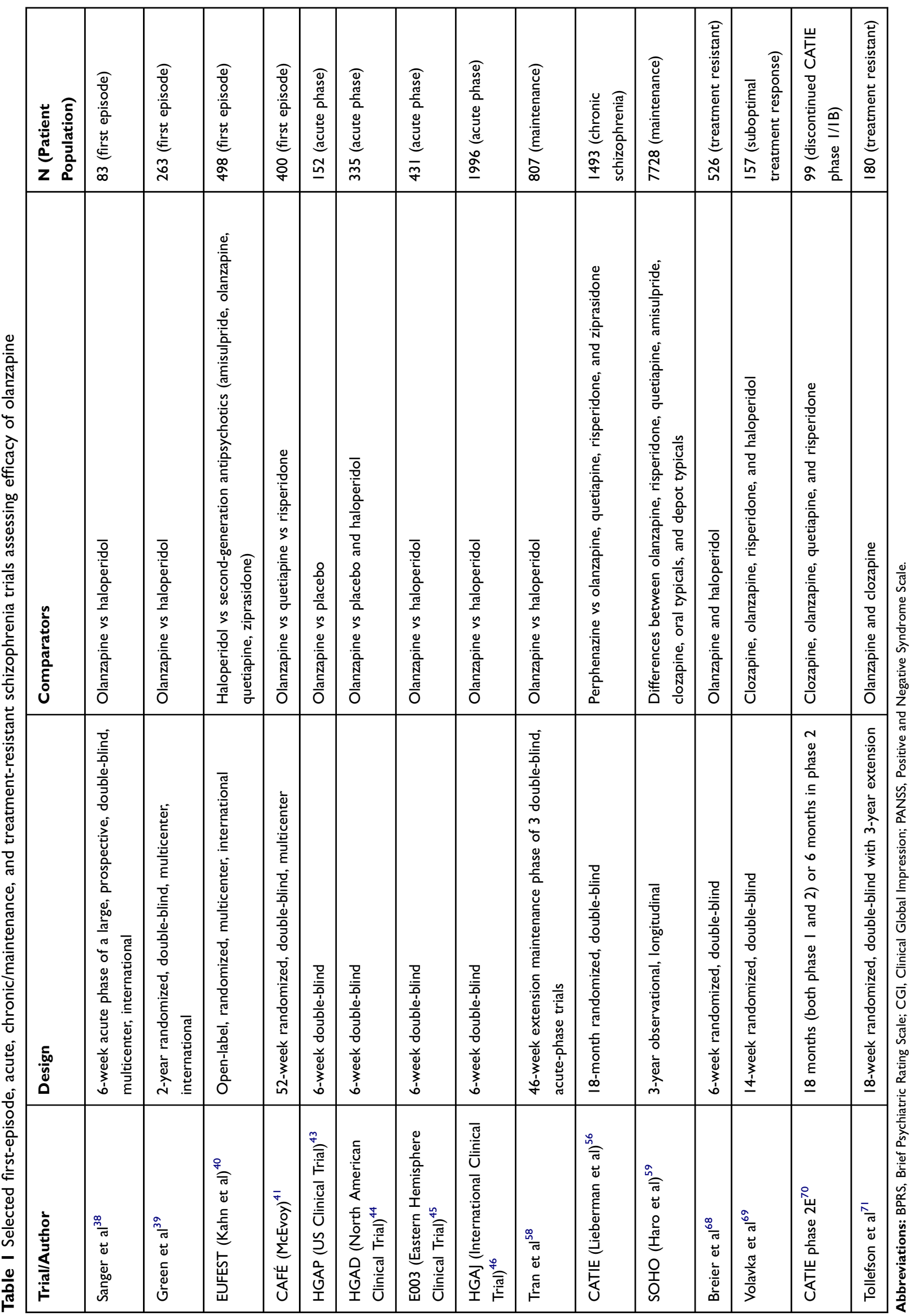




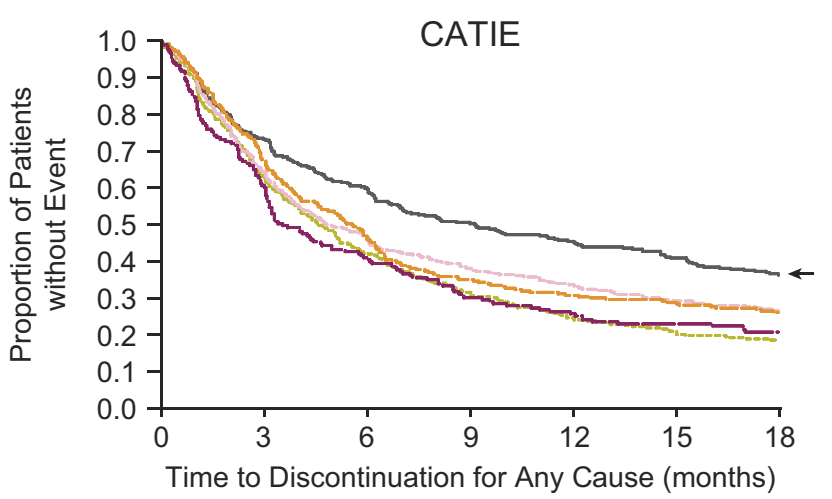

$\begin{array}{lll}- \text { Olanzapine } & - \text { Quetiapine } \\ - \text { Ziprasidone } & \text { Risperidone }\end{array}$

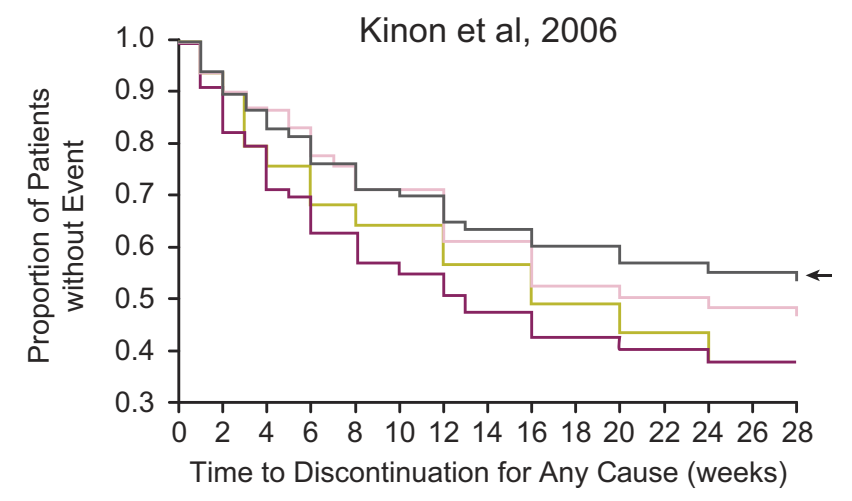

$\begin{array}{ll}- \text { Olanzapine } & - \text { Quetiapine } \\ - \text { Ziprasidone } & \text { Risperidone }\end{array}$

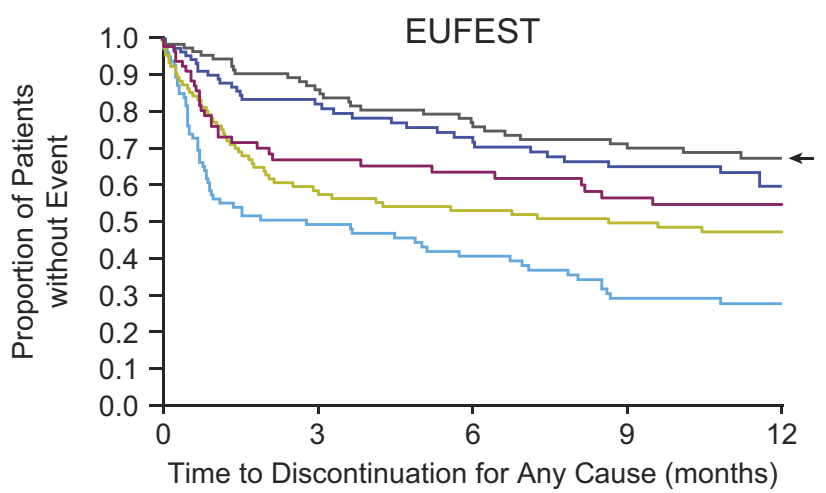

$\begin{array}{lll}- \text { Olanzapine } & - \text { Quetiapine }- \text { Haloperidol } \\ - \text { Ziprasidone } & \text { Amisulpride }\end{array}$

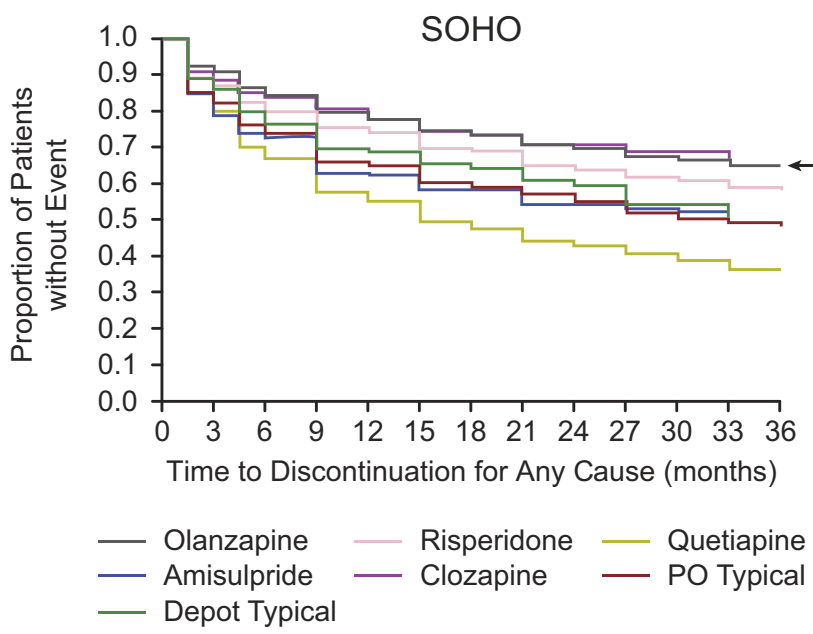

Figure I Time to all-cause discontinuation of antipsychotics across studies. Time to all-cause discontinuation is consistently longer with olanzapine compared with other first- and second-generation antipsychotics. CATIE: From New England Journal of Medicine. Lieberman et al. Effectiveness of antipsychotic drugs in patients with chronic schizophrenia. Volume 353, page 1219. Copyright (C2005 Massachusetts Medical Society. Reprinted with permission from Massachusetts Medical Society. ${ }^{56}$ EUFEST: Reprinted from The Lancet, Volume 37I, Kahn et al. Effectiveness of antipsychotic drugs in first-episode schizophrenia and schizophreniform disorder: an open randomised clinical trial, Pages 1085-1097, Copyright 2008, with permission from Elsevier. ${ }^{40}$ Kinon et al, 2006: Kinon et al, Differential rates of treatment discontinuation in clinical trials as a measure of treatment effectiveness for olanzapine and comparator atypical antipsychotics for schizophrenia. Journal of Clinical Psychopharmacology. 2006;26(6):632637. ${ }^{35} \mathrm{SOHO}$ : Reprinted from European Neuropsychopharmacology. Volume 17. Haro et al. Three-year antipsychotic effectiveness in the outpatient care of schizophrenia: observational versus randomized studies results. Pages 235-244. Copyright 2007, with permission from Elsevier. ${ }^{59}$

was associated with a more favorable efficacy profile, as evidenced by considerably lower rates of discontinuation due to lack of efficacy (14-19\% vs 25-48\%) during treatment with olanzapine compared with other antipsychotics. ${ }^{39,40}$ A post hoc analysis examining all-cause discontinuation rates from EUFEST found that treatment with olanzapine was associated with a number needed to treat (NNT) of 4 compared with haloperidol (indicating that 4 patients have to be treated with olanzapine instead of haloperidol to prevent 1 treatment discontinuation). For comparison, the NNT for quetiapine compared with haloperidol was $9 .^{42}$

Substantial improvements in several other efficacyrelated outcome measures have also been observed. Greater improvements in total BPRS score have been reported with olanzapine compared with haloperidol, with patients over 2 times more likely to achieve clinical response (defined as $\geq 40 \%$ improvement from baseline in BPRS total score) with olanzapine (67\% vs $29 \%$, respectively; $\mathrm{NNT}=3){ }^{38}$ Significantly greater reductions in PANSS positive subscale scores have also been reported with olanzapine following 1 year of follow-up compared with quetiapine. ${ }^{41}$ In the EUFEST study, olanzapine provided numerical but not statistically significant differences in PANSS score reductions versus haloperidol; however, remission rates significantly favored olanzapine (57\% vs $44 \%$; NNT $=8){ }^{39}$ Furthermore, in patients with first-episode schizophrenia, olanzapine was associated with a significantly greater reduction of hostility at 1 and 3 months 
compared with haloperidol, quetiapine, and amisulpride during the first 3 months of treatment. ${ }^{37}$

\section{Acute exacerbation in patients with schizophrenia}

Patients suffer a variety of positive psychotic symptoms during acute exacerbations of schizophrenia, including delusions, hallucinations, and thought disorder, which may be present along with other associated behaviors (such as agitation and aggression). ${ }^{11}$ In addition, negative and affective symptoms may be the focus of intervention. ${ }^{11}$ During exacerbations, the goal of treatment is to reduce the severity of psychosis and associated symptoms as quickly as possible, and to formulate short- and long-term treatment plans to prevent relapse and slow or limit disease progression. ${ }^{11}$

The initial efficacy of olanzapine in acute schizophrenia was based on data from 4 pivotal, 6-week, doubleblind trials in which reductions in BPRS total scores were significantly or numerically greater with olanzapine compared to placebo and haloperidol. ${ }^{43-46}$ Subsequently, the efficacy of olanzapine in the treatment of acute exacerbations has been confirmed in several randomized, doubleblind studies using the PANSS. ${ }^{47-50}$ Similar to findings in first-episode schizophrenia patients, ${ }^{37}$ olanzapine was also reported to be more effective than haloperidol in reducing aggressive behavior in a study that specifically enrolled physically assaultive patients with schizophrenia. ${ }^{51}$

The efficacy of olanzapine in the treatment of acute exacerbations is supported by a meta-analysis involving direct and indirect comparisons of 212 randomized controlled studies of 15 first- and second-generation antipsychotics. ${ }^{34}$ Olanzapine was among 4 antipsychotics (which also included clozapine, amisulpride, and risperidone) determined to be significantly more effective than other choices in the acute treatment of schizophrenia, based on improvements in PANSS or BPRS scores, and among 5 antipsychotics (also including amisulpride, clozapine, paliperidone, and risperidone) associated with significantly lower rates of all-cause discontinuation. ${ }^{34}$ This latter finding is hypothesized to be related, at least in part, to the emergence of improved insight during olanzapine treatment and subsequent downstream effects. ${ }^{52}$

\section{Beyond acute treatment: long-term outcomes}

Up to $50 \%$ of patients with schizophrenia do not adhere to treatment in the short term, and approximately $75 \%$ experience recurrent relapse and continued disability. ${ }^{53}$ As such, long-term treatment of schizophrenia is focused on sustaining symptom remission, maintaining (or improving) the patient's level of functioning and quality of life, and supporting patient adherence to recommended treatment over time. ${ }^{11}$ The long-term effectiveness of olanzapine has been established across a number of long-term outcome domains, including relapse prevention (defined as preventing or delaying recurrence of acute exacerbations of the symptoms of schizophrenia, assessed by rates of hospitalization), ${ }^{54}$ robustness of response (defined as the relative absence of active schizophrenia symptoms during long-term treatment, assessed by rates of remission), ${ }^{55}$ and durability of therapy (defined as the relative duration of time the patient remains on any given antipsychotic, commonly assessed by allcause discontinuation and subjective response). ${ }^{56,57}$

One of the initial studies assessing the long-term efficacy of olanzapine was an extension study ${ }^{58}$ for patients who responded well to treatment in olanzapine's pivotal acute-phase trials. ${ }^{43-46}$ Time to relapse, defined as hospitalization for psychopathology, was significantly lower for olanzapine than haloperidol, with a 1-year risk of relapse of $20 \%$ compared with $28 \%$ for haloperidol. ${ }^{58}$ Data from 2 large studies comparing the efficacy of first- and secondgeneration antipsychotics, the Clinical Antipsychotic Trials of Intervention Effectiveness (CATIE) ${ }^{56}$ study and the Schizophrenia Outpatient Health Outcomes (SOHO) study, ${ }^{59}$ consistently found that olanzapine had lower rates of hospitalization for exacerbation of schizophrenia. Further, in the CATIE study, the rate of remission, based on the Andreasen Criteria, ${ }^{55}$ was highest for olanzapine (12\% vs $6-8 \%$ with other antipsychotics). ${ }^{60}$ Olanzapine also had the highest rate of remission, based on CGI scores, in the SOHO study. ${ }^{61}$

In the long-term management of schizophrenia, it is important to understand the significance patients and providers place on the benefits and risks of different antipsychotics when making treatment decisions. Surveys have found that improvements in the positive symptoms of schizophrenia are ultimately more important to both healthcare providers and patients than avoiding adverse side effects of antipsychotics such as weight gain and extrapyramidal symptoms, ${ }^{57,62}$ although more severe adverse events may shift this opinion in the other direction. Likewise, in an analysis of data from 32 schizophrenia trials, discontinuation of medication was largely driven by lack of efficacy rather than intolerability. ${ }^{63}$ Therefore, a key finding supportive of the distinctly favorable efficacy of olanzapine is its durability of treatment. As shown in Figure 1, time to all- 
cause discontinuation is consistently longer for olanzapine compared with other antipsychotics. ${ }^{35,40,56,59}$ In CATIE, only $15 \%$ of patients treated with olanzapine discontinued treatment due to lack of efficacy, as compared with 24-28\% of patients treated with other antipsychotics. ${ }^{56}$ Further, a naturalistic study comparing olanzapine, risperidone, and haloperidol found better subjective response and compliance in patients treated with olanzapine compared with the other antipsychotics. ${ }^{64}$ Collectively, these data suggest that patients taking olanzapine remain on treatment longer, despite the drug's known side effects, than do patients taking other antipsychotics, potentially owing to olanzapine's superior efficacy.

Furthermore, post hoc analysis of data from the CATIE study identified a significant difference in favor of olanzapine for hostility in schizophrenia, ${ }^{36}$ consistent with the post hoc analysis of hostility in first-episode patients from the EUFEST study. ${ }^{37}$

\section{Suboptimal treatment response}

Treatment resistance, commonly defined as little or no symptomatic response to at least 2 previous antipsychotics, occurs in approximately $10-30 \%$ of patients with schizophrenia. ${ }^{11}$ This definition is used as the criteria for recommending treatment with clozapine. ${ }^{65}$ It is also not uncommon for patients to experience partial response to a prescribed antipsychotic with a clinical status that lies somewhere between full responder and treatment resistance. $^{65,66}$ The management of these patients is a major challenge and constitutes a serious public health concern given the associated social and economic burden. ${ }^{67}$

The use of olanzapine in patients with treatment-resistant schizophrenia or suboptimal response has been evaluated in several studies. ${ }^{68-74}$ In a study of patients with suboptimal treatment response randomized to olanzapine, clozapine, risperidone, or haloperidol, improvements in global psychopathology were significantly greater at week 14 with olanzapine compared with haloperidol. ${ }^{69}$ In phase $2 \mathrm{E}$ of the CATIE study, which included patients who discontinued from phase 1 primarily due to lack of efficacy, no significant differences were found between clozapine and olanzapine with regard to all-cause discontinuation or improvements in PANSS total score at 3 months, with clozapine being superior to treatment with either quetiapine or risperidone. ${ }^{70}$ Other studies in patients with treatment-resistant schizophrenia or suboptimal treatment response have also reported similar reductions with olanzapine and clozapine in PANSS total score, CGI severity score, and BPRS total score. ${ }^{69,71-73}$

In many of the aforementioned studies, olanzapine dosages above the maximum recommended dose of $20 \mathrm{mg} /$ day were used in treatment-resistant patients. ${ }^{13}$ This is not without controversy, as doses of $40 \mathrm{mg}$ /day did not confer an advantage over lower doses in a large $(\mathrm{N}=599)$ randomized clinical trial of patients with suboptimal response to their current treatment (but who were not defined as treatment resistant). ${ }^{75}$

\section{Safety}

The safety profile of olanzapine has been reviewed extensively elsewhere. ${ }^{3,76-79}$ In brief, second-generation antipsychotics are generally better tolerated than are the firstgeneration antipsychotics with regard to antipsychoticinduced movement disorders. ${ }^{33}$ However, many of these drugs are associated with clinically significant metabolic disturbances, including increased risk of diabetes, dyslipidemia, and weight gain. ${ }^{80}$ Olanzapine has one of the highest risks for metabolic syndrome among the secondgeneration atypical antipsychotics, especially during long-term treatment and with the administration of high doses, in accordance with a report from professional associations of psychiatrists, endocrinologists, and diabetologists. $^{81}$ In particular, hypertriglyceridemia can represent a sensitive marker of insulin resistance, a condition that induces obesity, especially central obesity, a primary risk factor for metabolic syndrome. ${ }^{82}$ In a recent animal model study, olanzapine exacerbated atherosclerosis by deregulating hepatic lipid metabolism and worsening hyperlipidemia and aortic inflammation. ${ }^{83}$ Antagonistic effects of olanzapine at $5-\mathrm{HT}_{2 \mathrm{c}}$, histaminergic $\mathrm{H} 1$, and muscarinic $\mathrm{M} 3$ receptors have been implicated in olanzapine-induced weight gain. Although a 2010 metaanalysis $^{84}$ reported significantly less weight gain when adjunctive metformin, fenfluramine, sibutramine, topiramate, and reboxetine versus placebo were added on to olanzapine therapy, and more recent studies support the efficacy of betahistine, ${ }^{85-88}$ to date, data are insufficient to recommend the routine use of any of these medications to mitigate olanzapine-induced weight gain. ${ }^{84,85}$

Olanzapine's adverse effects on glucose and lipid metabolism, weight, and body composition are of serious concern and require close monitoring. ${ }^{77}$ In an analysis of 13 short-term, placebo-controlled olanzapine monotherapy studies (median exposure: 6 weeks), the average weight gain with olanzapine was $2.6 \mathrm{~kg}(5.7 \mathrm{lb})$ compared to a 
weight loss of $0.3 \mathrm{~kg}(0.6 \mathrm{lb})$ with placebo. The percentage of patients who gained at least $7 \%$ of their baseline weight was $22 \%$ with olanzapine versus $3 \%$ with placebo. ${ }^{1}$ In long-term studies (at least 48 weeks), 64\%, 32\%, and $12 \%$ of patients gained $7 \%, 15 \%$, or $25 \%$ or more of their baseline body weight, respectively. ${ }^{1}$ Shifts from nor$\mathrm{mal} /$ borderline to abnormal plasma glucose or lipid variables have also been observed and are a concern. ${ }^{77,89}$ Several guidelines and publications have included strategies to help mitigate these side effects, such as with concomitant off-label use of metformin, as well as greater attention to promoting positive lifestyle modifications with respect to diet and exercise. ${ }^{9,80,90-92}$ However, there are currently no FDA-approved treatments indicated to mitigate the metabolic dysregulation, including weight gain, associated with olanzapine or any other currently available atypical antipsychotics.

Despite these well-known adverse metabolic effects, olanzapine does have some safety advantages relative to other antipsychotics. Olanzapine is associated with a lower incidence of extrapyramidal symptoms than typical and some atypical antipsychotics, ${ }^{93,94}$ an important cause of noncompliance and treatment discontinuation. ${ }^{95}$ Further, agranulocytosis, a potentially fatal adverse event that limits clozapine's use, ${ }^{96}$ was not reported in any of the more than 2000 patients receiving olanzapine in the 4 pivotal efficacy and safety trials. ${ }^{43-46}$ Olanzapine also has generally little impact on prolactin compared with some typical and atypical antipsychotics. ${ }^{33}$ A significantly lower proportion of patients had elevations in prolactin during treatment with olanzapine compared with haloperidol (18-35\% vs $82 \%)^{45}$ or with risperidone ( $51 \%$ vs $\left.94 \%\right) .{ }^{97}$ Although prolactin effects with olanzapine are likely dose related, ${ }^{75}$ increases in prolactin associated with olanzapine were generally mild, transient, and of lesser magnitude than haloperidol and risperidone. ${ }^{44-46,97}$ Several studies have subsequently confirmed a favorable impact of olanzapine on prolactin levels. ${ }^{98-100}$ As a result, patients taking olanzapine may be at reduced risk for complications of hyperprolactinemia, including gynecomastia, galactorrhea, menstrual irregularities, and sexual dysfunction, compared with other antipsychotics. ${ }^{101}$ Lastly, olanzapine treatment was associated with a low incidence of seizures, 22/2500 $(0.9 \%)$, during premarketing studies. ${ }^{1}$ Based on this finding, the Epilepsy Foundation lists olanzapine as 1 of 3 antipsychotics recommended on the basis of both epileptogenesis and side effect profile. ${ }^{102}$

\section{Summary}

Two decades ago, the safety risks associated with olanzapine were not as well understood as they are today. Now, olanzapine is no longer the first choice of treatment for patients with schizophrenia. Even so, olanzapine remains widely used, lending indirect support to the hypothesis that olanzapine's effectiveness differs from other antipsychotic treatment options. This commentary aims to highlight the significant body of data supporting the hypothesis that olanzapine may be more effective than other non-clozapine antipsychotics currently considered the first choice of treatment for schizophrenia. Although our focus was to highlight olanzapine's unique efficacy qualities, we acknowledge that olanzapine's efficacy is not a universal finding across all studies; however, for the purposes of the current commentary, it was not our intention to conduct an exhaustive meta-analysis. The relative efficacy seems to depend, in part, on the clinical situation in which it is used. Collectively, these data suggest that if efficacy alone were the only consideration, olanzapine may be a preferred first-line treatment option for patients with chronic schizophrenia requiring effective long-term treatment (ie, for prevention of relapse, robustness of response, and treatment persistence aspects) and in those with suboptimal responses during treatment with other antipsychotics. Despite the known risk for metabolic side effects, including weight gain, olanzapine continues to be prescribed due to the overall favorable drug profile. As with any treatment, selection of the most appropriate antipsychotic agent for patients with schizophrenia must be individualized and thoughtfully considered, taking into account both the benefits and risks associated with its use. Therefore, the development of interventions that offer the efficacy of olanzapine but reduce the weight gain and potential long-term complications associated with its use could address a major unmet need in the treatment of schizophrenia. These interventions could include agents with new mechanisms of action or single-pill combination products that contain both olanzapine and agent(s) that could potentially mitigate olanzapine's propensity for weight gain to serve as potential alternatives in clinical situations in which olanzapine would have been considered.

\section{Abbreviations}

BPRS, Brief Psychiatric Rating Scale; CATIE, Clinical Antipsychotic Trials of Intervention Effectiveness; CGI, Clinical Global Impression; EUFEST, European First- 
Episode Schizophrenia Trial; FDA, US Food and Drug Administration; NNT, number needed to treat; PANSS, Positive and Negative Syndrome Scale; SOHO, Schizophrenia Outpatient Health Outcomes.

\section{Acknowledgments}

This study was sponsored by Alkermes, Inc. Medical writing and editorial support was provided by Peloton Advantage, LLC, an OPEN Health company, Parsippany, $\mathrm{NJ}$, and funded by Alkermes, Inc. Alkermes, Inc. is developing a combination product of olanzapine and samidorphan for the treatment of schizophrenia, and has funded the development of this manuscript.

\section{Disclosures}

LC has, in the past 5 years, engaged in collaborative research with, or received consulting or speaking fees, from: Acadia, Alexza, Alkermes, Allergan, AstraZeneca, Avanir, Boehringer Ingelheim, Bristol-Myers Squibb, Eli Lilly, Forum, Genentech, Intra-Cellular Therapeutics, Janssen, Jazz, Lundbeck, Merck, Medivation, Mylan, Neurocrine, Novartis, Noven, Otsuka, Pfizer, Indivior/ Reckitt Benckiser, Reviva, Shire, Sunovion, Takeda, Teva, Valeant, Vanda. In the past 12 months, consultant: Acadia, Alkermes, Allergan, Indivior, Intra-Cellular Therapeutics, Janssen, Lundbeck, Merck, Neurocrine, Noven, Osmotica, Otsuka, Pfizer, Shire, Sunovion, Takeda, Teva, Vanda. In the past 12 months, speaker: Acadia, Alkermes, Allergan, Janssen, Lundbeck, Merck, Neurocrine, Otsuka, Pfizer, Shire, Sunovion, Takeda, Teva. Stocks (small number of shares of common stock): BristolMyers Squibb, Eli Lilly, J \& J, Merck, Pfizer purchased $>10$ years ago. Royalties: Wiley (Editor-in-Chief, International Journal of Clinical Practice), UpTo Date (reviewer), Springer Healthcare (book). JPM serves on advisory boards for Neurocrine and Alkermes. MST, DM, and PJW are full-time employees of Alkermes, Inc., and may own stock in the company.

\section{References}

1. Zyprexa [package Insert]. Indianapolis (IN): Eli Lilly and Company; 2018.

2. Zyprexa (Olanzapine) new drug approval package. 1996. Available from: https://www.accessdata.fda.gov/drugsatfda_docs/nda/96/ 020592_Original_Approval_Pkg\%20.pdf. Accessed September 26, 2018.

3. Komossa K, Rummel-Kluge C, Hunger H, et al. Olanzapine versus other atypical antipsychotics for schizophrenia. Cochrane Database Syst Rev. 2010;3:CD006654.
4. Leucht S, Pitschel-Walz G, Abraham D, Kissling W. Efficacy and extrapyramidal side-effects of the new antipsychotics olanzapine, quetiapine, risperidone, and sertindole compared to conventional antipsychotics and placebo. A meta-analysis of randomized controlled trials. Schizophr Res. 1999;35(1):51-68.

5. Davis JM, Chen N. The effects of olanzapine on the 5 dimensions of schizophrenia derived by factor analysis: combined results of the North American and international trials. J Clin Psychiatry. 2001;62(10):757-771.

6. Davis JM, Chen N, Glick ID. A meta-analysis of the efficacy of second-generation antipsychotics. Arch Gen Psychiatry. 2003;60 (6):553-564. doi:10.1001/archpsyc.60.6.553

7. Buchanan RW, Kreyenbuhl J, Kelly DL, et al. The 2009 schizophrenia PORT psychopharmacological treatment recommendations and summary statements. Schizophr Bull. 2010;36(1):7193. doi: $10.1093 / \mathrm{schbul} / \mathrm{sbp} 116$

8. Osser DN, Roudsari MJ, Manschreck T. The psychopharmacology algorithm project at the Harvard South Shore Program: an update on schizophrenia. Harv Rev Psychiatry. 2013;21(1):18-40. doi:10.1097/HRP.0b013e31827fd915

9. Galletly C, Castle D, Dark F, et al. Royal Australian and New Zealand College of Psychiatrists clinical practice guidelines for the management of schizophrenia and related disorders. Aust N Z J Psychiatry. 2016;50(5):410-472. doi:10.1177/0004867416641195

10. Keating D, McWilliams S, Schneider I, et al. Pharmacological guidelines for schizophrenia: a systematic review and comparison of recommendations for the first episode. BMJ Open. 2017;7(1): e013881. doi:10.1136/bmjopen-2016-013881

11. Lehman AF, Lieberman JA, Dixon LB, et al. Practice Guideline for the Treatment of Patients with Schizophrenia. 2nd ed; 2010. Available from: https://psychiatryonline.org/pb/assets/raw/sitewide/practice guidelines/guidelines/schizophrenia.pdf. Accessed January 28, 2019.

12. Agid O, Foussias G, Singh S, Remington G. Where to position clozapine: re-examining the evidence. Can J Psychiatry. 2010;55 (10):677-684. doi:10.1177/070674371005501007

13. Citrome L, Kantrowitz JT. Olanzapine dosing above the licensed range is more efficacious than lower doses: fact or fiction? Expert Rev Neurother. 2009;9(7):1045-1058. doi:10.1586/ern.09.54

14. Society for Medicines Research. Case histories of drug discovery. 1999. Available from: https://www.smr.org.uk/smr/archive/pastmeet ings/Downloads/19991202.pdf. Accessed September 26, 2018.

15. Shen WW. The metabolism of atypical antipsychotic drugs: an update. Ann Clin Psychiatry. 1999;11(3):145-158.

16. Bymaster FP, Calligaro DO, Falcone JF, et al. Radioreceptor binding profile of the atypical antipsychotic olanzapine. Neuropsychopharmacology. 1996;14(2):87-96. doi:10.1016/089 3-133X(94)00129-N

17. Fuller RW, Snoddy HD. Neuroendocrine evidence for antagonism of serotonin and dopamine receptors by olanzapine (LY170053), an antipsychotic drug candidate. Res Commun Chem Pathol Pharmacol. 1992;77(1):87-93.

18. Moore NA, Tye NC, Axton MS, Risius FC. The behavioral pharmacology of olanzapine, a novel "atypical" antipsychotic agent. J Pharmacol Exp Ther. 1992;262(2):545-551.

19. Pan B, Lian J, Deng C. Chronic antipsychotic treatment differentially modulates protein kinase A- and glycogen synthase kinase 3 beta-dependent signaling pathways, N-methyl-D-aspartate receptor and gamma-aminobutyric acid A receptors in nucleus accumbens of juvenile rats. J Psychopharmacol (Oxford). 2018;32 (11):1252-1263. doi:10.1177/0269881118788822

20. Krzystanek M, Bogus K, Palasz A, Krzystanek E, Worthington JJ, Wiaderkiewicz R. Effects of long-term treatment with the neuroleptics haloperidol, clozapine and olanzapine on immunoexpression of NMDA receptor subunits NR1, NR2A and NR2B in the rat hippocampus. Pharmacol Rep. 2015;67(5):965-969. doi:10.10 16/j.pharep.2015.01.017 
21. Baldwin DS, Montgomery SA. First clinical experience with olanzapine (LY 170053): results of an open-label safety and dose-ranging study in patients with schizophrenia. Int Clin Psychopharmacol. 1995;10(4):239-244.

22. Zyprexa [orginial Package Insert]. Indianapolis (IN): Eli Lilly and Company; 1996.

23. Duggan L, Fenton M, Rathbone J, Dardennes R, El-Dosoky A, Indran S. Olanzapine for schizophrenia. Cochrane Database Syst Rev. 2005;(2):CD001359.

24. Owen MJ, Sawa A, Mortensen PB. Schizophrenia. Lancet. 2016;388(10039):86-97. doi:10.1016/S0140-6736(15)01121-6

25. Juckel G, de Bartolomeis A, Gorwood P, et al. Towards a framework for treatment effectiveness in schizophrenia. Neuropsychiatr Dis Treat. 2014;10:1867-1878. doi:10.2147/NDT.S61672

26. Correll CU, Kishimoto T, Nielsen J, Kane JM. Quantifying clinical relevance in the treatment of schizophrenia. Clin Ther. 2011;33(12):B16-39. doi:10.1016/j.clinthera.2011.11.016

27. Kumari S, Malik M, Florival C, Manalai P, Sonje S. An assessment of five (PANSS, SAPS, SANS, NSA-16, CGI-SCH) commonly used symptoms rating scales in schizophrenia and comparison to newer scales (CAINS, BNSS). J Addict Res Ther. 2017;8(3). doi:10.4172/2155-6105.1000324

28. Mortimer AM. Symptom rating scales and outcome in schizophrenia. Br J Psychiatry Suppl. 2007;50:s7-s14. doi:10.1192/ bjp.191.50.s7

29. Busner J, Targum SD. The clinical global impressions scale: applying a research tool in clinical practice. Psychiatry (Edgmont). 2007;4(7):28-37.

30. Overall JE, Gorham DR. The brief psychiatric rating scale. Psychol Rep. 1962;10(3):799-812. doi:10.2466/pr0.1962.10.3.799

31. Haro JM, Kamath SA, Ochoa S, et al. The clinical global impression-schizophrenia scale: a simple instrument to measure the diversity of symptoms present in schizophrenia. Acta Psychiatr Scand Suppl. 2003;(416):16-23. doi:10.1034/j.1600-0447.107.s416.5.x

32. Kay SR, Fiszbein A, Opler LA. The positive and negative syndrome scale (PANSS) for schizophrenia. Schizophr Bull. 1987;13 (2):261-276. doi:10.1093/schbul/13.2.261

33. Volavka J, Citrome L. Oral antipsychotics for the treatment of schizophrenia: heterogeneity in efficacy and tolerability should drive decision-making. Expert Opin Pharmacother. 2009;10 (12):1917-1928. doi:10.1517/14656560903061309

34. Leucht S, Cipriani A, Spineli L, et al. Comparative efficacy and tolerability of 15 antipsychotic drugs in schizophrenia: a multipletreatments meta-analysis. Lancet. 2013;382(9896):951-962. doi:10.1016/S0140-6736(13)60733-3

35. Kinon BJ, Liu-Seifert H, Adams DH, Citrome L. Differential rates of treatment discontinuation in clinical trials as a measure of treatment effectiveness for olanzapine and comparator atypical antipsychotics for schizophrenia. J Clin Psychopharmacol. 2006;26(6):632-637. doi:10.1097/01.jcp.0000245563.06660.0f

36. Volavka J, Czobor P, Citrome L, Van Dorn RA. Effectiveness of antipsychotic drugs against hostility in patients with schizophrenia in the Clinical Antipsychotic Trials of Intervention Effectiveness (CATIE) study. CNS Spectr. 2014;19(5):374-381. doi:10.1017/S1092852913000849

37. Volavka J, Czobor P, Derks EM, et al. Efficacy of antipsychotic drugs against hostility in the European First-Episode Schizophrenia Trial (EUFEST). J Clin Psychiatry. 2011;72 (7):955-961. doi:10.4088/JCP.10m06529

38. Sanger TM, Lieberman JA, Tohen M, Grundy S, Beasley C Jr., Tollefson GD. Olanzapine versus haloperidol treatment in firstepisode psychosis. Am $J$ Psychiatry. 1999;156(1):79-87. doi:10.1176/ajp.156.1.79

39. Green AI, Lieberman JA, Hamer RM, et al. Olanzapine and haloperidol in first episode psychosis: two-year data. Schizophr Res. 2006;86(1-3):234-243. doi:10.1016/j.schres.2006.06.021
40. Kahn RS, Fleischhacker WW, Boter H, et al. Effectiveness of antipsychotic drugs in first-episode schizophrenia and schizophreniform disorder: an open randomised clinical trial. Lancet. 2008;371 (9618):1085-1097. doi:10.1016/S0140-6736(08)60486-9

41. McEvoy JP, Lieberman JA, Perkins DO, et al. Efficacy and tolerability of olanzapine, quetiapine, and risperidone in the treatment of early psychosis: a randomized, double-blind 52-week comparison. Am J Psychiatry. 2007;164(7):1050-1060. doi:10. 1176/ajp.2007.164.7.1050

42. Citrome L. Interpreting and applying the EUFEST results using number needed to treat: antipsychotic effectiveness in first-episode schizophrenia. Int $J$ Clin Pract. 2008;62(5):837-840. doi:10.1111/j.1742-1241.2008.01758.x

43. Beasley CM Jr., Sanger T, Satterlee W, Tollefson G, Tran P, Hamilton S. Olanzapine versus placebo: results of a doubleblind, fixed-dose olanzapine trial. Psychopharmacology (Berl). 1996;124(1-2):159-167. doi:10.1007/bf02245617

44. Beasley CM Jr., Tollefson G, Tran P, Satterlee W, Sanger T, Hamilton S. Olanzapine versus placebo and haloperidol: acute phase results of the North American double-blind olanzapine trial. Neuropsychopharmacology. 1996;14(2):111-123. doi:10.1016/ 0893-133X(95)00069-P

45. Beasley CM Jr., Hamilton SH, Crawford AM, et al. Olanzapine versus haloperidol: acute phase results of the international double-blind olanzapine trial. Eur Neuropsychopharmacol. 1997;7 (2):125-137.

46. Tollefson GD, Beasley CM Jr., Tran PV, et al. Olanzapine versus haloperidol in the treatment of schizophrenia and schizoaffective and schizophreniform disorders: results of an international collaborative trial. Am J Psychiatry. 1997;154(4):457-465. doi:10.11 76/ajp.154.4.457

47. Svestka J, Synek O, Zourkova A. A double-blind comparison of olanzapine and quetiapine in treatment of acute exacerbations of schizophrenic or schizoaffective disorders [abstract P.2.031]. Eur Neuropsychopharmacol. 2003;13(4):S292. doi:10.1016/S0924977X(03)91984-5

48. Riedel M, Muller N, Spellmann I, et al. Efficacy of olanzapine versus quetiapine on cognitive dysfunctions in patients with an acute episode of schizophrenia. Eur Arch Psychiatry Clin Neurosci. 2007;257(7):402-412. doi:10.1007/s00406007-0748-9

49. Grootens KP, van Veelen NM, Peuskens J, et al. Ziprasidone vs olanzapine in recent-onset schizophrenia and schizoaffective disorder: results of an 8-week double-blind randomized controlled trial. Schizophr Bull. 2011;37(2):352-361. doi:10.1093/schbul/ sbp037

50. McQuade RD, Stock E, Marcus R, et al. A comparison of weight change during treatment with olanzapine or aripiprazole: results from a randomized, double-blind study. $J$ Clin Psychiatry. 2004;65(suppl 18):47-56.

51. Krakowski MI, Czobor P, Citrome L, Bark N, Cooper TB Atypical antipsychotic agents in the treatment of violent patients with schizophrenia and schizoaffective disorder. Arch Gen Psychiatry. 2006;63(6):622-629. doi:10.1001/archpsyc.63.6.622

52. He H, Zhou Y, Yang M, Li X, Xiang YT, Luo J. Comparison of olanzapine versus other second-generation antipsychotics in the improvement of insight and medication discontinuation rate in schizophrenia. Shanghai Arch Psychiatry. 2018;30(3):178-187. doi:10.11919/j.issn.1002-0829.217087

53. Smith TE, Weston CA, Lieberman JA. Schizophrenia (maintenance treatment). BMJ Clin Evid. 2009;2009:1007.

54. Csernansky JG, Schuchart EK. Relapse and rehospitalisation rates in patients with schizophrenia: effects of second generation antipsychotics. CNS Drugs. 2002;16(7):473-484. doi:10.2165/0002 3210-200216070-00004 
55. Andreasen NC, Carpenter WT Jr., Kane JM, Lasser RA, Marder SR, Weinberger DR. Remission in schizophrenia: proposed criteria and rationale for consensus. Am J Psychiatry. 2005;162 (3):441-449. doi:10.1176/appi.ajp.162.3.441

56. Lieberman JA, Stroup TS, McEvoy JP, et al. Effectiveness of antipsychotic drugs in patients with chronic schizophrenia. $N$ Engl J Med. 2005;353(12):1209-1223. doi:10.1056/NEJMoa05 1688

57. Levitan B, Markowitz M, Mohamed AF, et al. Patients' preferences related to benefits, risks, and formulations of schizophrenia treatment. Psychiatr Serv. 2015;66(7):719-726. doi:10.1176/appi. ps. 201400188

58. Tran PV, Dellva MA, Tollefson GD, Wentley AL, Beasley CM Jr. Oral olanzapine versus oral haloperidol in the maintenance treatment of schizophrenia and related psychoses. Br J Psychiatry. 1998;172:499-505. doi:10.1192/bjp.172.6.499

59. Haro JM, Suarez D, Novick D, Brown J, Usall J, Naber D. Three-year antipsychotic effectiveness in the outpatient care of schizophrenia: observational versus randomized studies results. Eur Neuropsychopharmacol. 2007;17(4):235-244. doi:10.1016/j. euroneuro.2006.09.005

60. Levine SZ, Rabinowitz J, Ascher-Svanum H, Faries DE, Lawson $\mathrm{AH}$. Extent of attaining and maintaining symptom remission by antipsychotic medication in the treatment of chronic schizophrenia: evidence from the CATIE study. Schizophr Res. 2011;133(13):42-46. doi:10.1016/j.schres.2011.09.018

61. Haro JM, Novick D, Suarez D, Alonso J, Lepine JP, Ratcliffe M. Remission and relapse in the outpatient care of schizophrenia: three-year results from the Schizophrenia Outpatient Health Outcomes study. J Clin Psychopharmacol. 2006;26(6):571-578. doi:10.1097/01.jcp.0000246215.49271.b8

62. Markowitz MA, Levitan BS, Mohamed AF, et al. Psychiatrists' judgments about antipsychotic benefit and risk outcomes and formulation in schizophrenia treatment. Psychiatr Serv. 2014;65 (9):1133-1139. doi:10.1176/appi.ps.201300290

63. Khin NA, Chen YF, Yang Y, Yang P, Laughren TP. Exploratory analyses of efficacy data from schizophrenia trials in support of new drug applications submitted to the US Food and Drug Administration. $J$ Clin Psychiatry. 2012;73(6):856-864. doi:10.4088/JCP.11r07539

64. Garcia-Cabeza I, Gomez JC, Sacristan JA, Edgell E, Gonzalez de Chavez M. Subjective response to antipsychotic treatment and compliance in schizophrenia. A naturalistic study comparing olanzapine, risperidone and haloperidol (EFESO Study). BMC Psychiatry. 2001;1:7. doi:10.1186/1471-244X-1-7

65. Weiden PJ. How many treatments before clozapine? medication choices across the spectrum of treatment resistance in schizophrenia. J Clin Psychiatry. 2016;77(5):e594-e596. doi:10.4088/JCP. 16 com 10797

66. Schooler NR, Marder SR, Chengappa KN, et al. Clozapine and risperidone in moderately refractory schizophrenia: a 6-month randomized double-blind comparison. $J$ Clin Psychiatry. 2016;77(5):628-634. doi:10.4088/JCP.13m08351

67. Kennedy JL, Altar CA, Taylor DL, Degtiar I, Hornberger JC. The social and economic burden of treatment-resistant schizophrenia: a systematic literature review. Int Clin Psychopharmacol. 2014;29 (2):63-76. doi:10.1097/YIC.0b013e32836508e6

68. Breier A, Hamilton SH. Comparative efficacy of olanzapine and haloperidol for patients with treatment-resistant schizophrenia. Biol Psychiatry. 1999;45(4):403-411. doi:10.1016/s0006-3223 (98)00291-1

69. Volavka J, Czobor P, Sheitman B, et al. Clozapine, olanzapine, risperidone, and haloperidol in the treatment of patients with chronic schizophrenia and schizoaffective disorder. $\mathrm{Am} J$ Psychiatry. 2002;159(2):255-262. doi:10.1176/appi.ajp.159.2.255
70. McEvoy JP, Lieberman JA, Stroup TS, et al. Effectiveness of clozapine versus olanzapine, quetiapine, and risperidone in patients with chronic schizophrenia who did not respond to prior atypical antipsychotic treatment. Am $J$ Psychiatry. 2006;163(4):600-610. doi:10.1176/appi.ajp.163.4.600

71. Tollefson GD, Birkett MA, Kiesler GM, Wood AJ. Doubleblind comparison of olanzapine versus clozapine in schizophrenic patients clinically eligible for treatment with clozapine. Biol Psychiatry. 2001;49(1):52-63. doi:10.1016/s0006-3223 (00)01026-x

72. Bitter I, Dossenbach MR, Brook S, et al. Olanzapine versus clozapine in treatment-resistant or treatment-intolerant schizophrenia. Prog Neuropsychopharmacol Biol Psychiatry. 2004;28 (1):173-180. doi:10.1016/j.pnpbp.2003.09.033

73. Meltzer HY, Bobo WV, Roy A, et al. A randomized, double-blind comparison of clozapine and high-dose olanzapine in treatmentresistant patients with schizophrenia. J Clin Psychiatry. 2008;69 (2):274-285.

74. Samara MT, Dold M, Gianatsi M, et al. Efficacy, acceptability, and tolerability of antipsychotics in treatment-resistant schizophrenia: a network meta-analysis. JAMA Psychiatry. 2016;73 (3):199-210. doi:10.1001/jamapsychiatry.2015.2955

75. Kinon BJ, Volavka J, Stauffer V, et al. Standard and higher dose of olanzapine in patients with schizophrenia or schizoaffective disorder: a randomized, double-blind, fixed-dose study. $J$ Clin Psychopharmacol. 2008;28(4):392-400. doi:10.1097/JCP.0b013e 31817e63a5

76. Kantrowitz JT, Citrome L. Olanzapine: review of safety 2008. Expert Opin Drug Saf. 2008;7(6):761-769. doi:10.1517/14740 330802423234

77. Citrome L, Holt RI, Walker DJ, Hoffmann VP. Weight gain and changes in metabolic variables following olanzapine treatment in schizophrenia and bipolar disorder. Clin Drug Investig. 2011;31 (7):455-482. doi:10.2165/11589060-000000000-00000

78. Kelly DL, Conley RR, Carpenter WT. First-episode schizophrenia: a focus on pharmacological treatment and safety considerations. Drugs. 2005;65(8):1113-1138. doi:10.2165/00003495-200 565080-00006

79. Czekalla J, Kollack-Walker S, Beasley CM Jr. Cardiac safety parameters of olanzapine: comparison with other atypical and typical antipsychotics. J Clin Psychiatry. 2001;62(suppl 2):35-40.

80. De Hert M, Detraux J, van Winkel R, Yu W, Correll CU. Metabolic and cardiovascular adverse effects associated with antipsychotic drugs. Nat Rev Endocrinol. 2012;8(2):114-126. doi:10.1038/nrendo.2011.156

81. American Diabetes Association, American Psychiatric Association, American Association of Clinical Endocrinologists, North American Association for the Study of Obesity. Consensus development conference on antipsychotic drugs and obesity and diabetes. J Clin Psychiatry. 2004;65(2):267-272.

82. Meyer JM, Stahl SM. The metabolic syndrome and schizophrenia. Acta Psychiatr Scand. 2009;119(1):4-14. doi:10.1111/j.16000447.2008.01317.x

83. Chen CH, Shyue SK, Hsu CP, Lee TS. Atypical antipsychotic drug olanzapine deregulates hepatic lipid metabolism and aortic inflammation and aggravates atherosclerosis. Cell Physiol Biochem. 2018;50(4):1216-1229. doi:10.1159/000494573

84. Maayan L, Correll CU. Management of antipsychotic-related weight gain. Expert Rev Neurother. 2010;10(7):1175-1200. doi:10.1586/ern.10.85

85. Smith RC, Maayan L, Wu R, et al. Betahistine effects on weight-related measures in patients treated with antipsychotic medications: a double-blind placebo-controlled study. Psych opharmacology (Berl). 2018;235(12):3545-3558. doi:10.100 7/s00213-018-5079-1 
86. Barak N, Beck Y, Albeck JH. Betahistine decreases olanzapineinduced weight gain and somnolence in humans. $J$ Psychopharmacol (Oxford). 2016;30(3):237-241. doi:10.1177/ 0269881115626349

87. Lian J, Huang XF, Pai N, Deng C. Ameliorating antipsychoticinduced weight gain by betahistine: mechanisms and clinical implications. Pharmacol Res. 2016;106:51-63. doi:10.1016/j. phrs.2016.02.011

88. Lian J, Huang XF, Pai N, Deng C. Preventing olanzapine-induced weight gain using betahistine: a study in a rat model with chronic olanzapine treatment. PLoS One. 2014;9(8):e104160. doi:10.13 71/journal.pone.0104160

89. Citrome L. Olanzapine: interpreting the label change. Int J Clin Pract. 2007;61(12):1960-1962. doi:10.1111/j.1742-1241.2007.01631.x

90. Dayabandara M, Hanwella R, Ratnatunga S, Seneviratne S, Suraweera C, de Silva VA. Antipsychotic-associated weight gain: management strategies and impact on treatment adherence. Neuropsychiatr Dis Treat. 2017;13:2231-2241. doi:10.2147/NDT. S113099

91. de Silva VA, Suraweera C, Ratnatunga SS, Dayabandara M, Wanniarachchi N, Hanwella R. Metformin in prevention and treatment of antipsychotic induced weight gain: a systematic review and meta-analysis. BMC Psychiatry. 2016;16(1):341. doi:10.1186/s12888-016-1049-5

92. Ventriglio A, Gentile A, Stella E, Bellomo A. Metabolic issues in patients affected by schizophrenia: clinical characteristics and medical management. Front Neurosci. 2015;9:297. doi:10.3389/ fnins.2015.00297

93. Tran PV, Dellva MA, Tollefson GD, Beasley CM Jr., Potvin JH, Kiesler GM. Extrapyramidal symptoms and tolerability of olanzapine versus haloperidol in the acute treatment of schizophrenia. J Clin Psychiatry. 1997;58(5):205-211.

94. Carlson CD, Cavazzoni PA, Berg PH, Wei H, Beasley CM, Kane JM. An integrated analysis of acute treatment-emergent extrapyramidal syndrome in patients with schizophrenia during olanzapine clinical trials: comparisons with placebo, haloperidol, risperidone, or clozapine. J Clin Psychiatry. 2003;64(8):898-906.
95. Perkins DO. Predictors of noncompliance in patients with schizophrenia. J Clin Psychiatry. 2002;63(12):11211128.

96. De Berardis D, Rapini G, Olivieri L, et al. Safety of antipsychotics for the treatment of schizophrenia: a focus on the adverse effects of clozapine. Ther Adv Drug Saf. 2018;9(5):237-256. doi:10.1177/2042098618756261

97. Tran PV, Hamilton SH, Kuntz AJ, et al. Double-blind comparison of olanzapine versus risperidone in the treatment of schizophrenia and other psychotic disorders. J Clin Psychopharmacol. 1997;17 (5):407-418.

98. Chen YL, Cheng TS, Lung FW. Prolactin levels in olanzapine treatment correlate with positive symptoms of schizophrenia: results from an open-label, flexible-dose study. Prim Care Companion J Clin Psychiatry. 2009;11(1):16-20. doi:10.4088/ pcc. $08 \mathrm{~m} 00668$

99. Costa AM, de Lima MS, Faria M, Filho SR, de Oliveira IR, de Jesus Mari J. A naturalistic, 9-month follow-up, comparing olanzapine and conventional antipsychotics on sexual function and hormonal profile for males with schizophrenia. $J$ Psychopharmacol (Oxford). 2007;21(2):165-170. doi:10.1177/02 69881107066333

100. Kinon BJ, Ahl J, Liu-Seifert H, Maguire GA. Improvement in hyperprolactinemia and reproductive comorbidities in patients with schizophrenia switched from conventional antipsych otics or risperidone to olanzapine. Psychoneuroendocrin ology. 2006;31(5):577-588. doi:10.1016/j.psyneuen.2005.12 006

101. Tewksbury A, Olander A. Management of antipsychotic-induced hyperprolactinemia. Ment Health Clin. 2016;6(4):185-190. doi: 10.9740/mhc.2016.07.185

102. Epilepsy Foundation. Antipsychotics. 2019. Available from: https://www.epilepsy.com/learn/professionals/diagnosis-trea ment/psychotropic-drugs-developmental-disabilities/comorbid-5. Accessed July 17, 2019.
Neuropsychiatric Disease and Treatment

\section{Publish your work in this journal}

Neuropsychiatric Disease and Treatment is an international, peerreviewed journal of clinical therapeutics and pharmacology focusing on concise rapid reporting of clinical or pre-clinical studies on a range of neuropsychiatric and neurological disorders. This journal is indexed on PubMed Central, the 'PsycINFO' database and CAS, and

\section{Dovepress}

is the official journal of The International Neuropsychiatric Association (INA). The manuscript management system is completely online and includes a very quick and fair peer-review system, which is all easy to use. Visit http://www.dovepress.com/testimonials.php to read real quotes from published authors. 